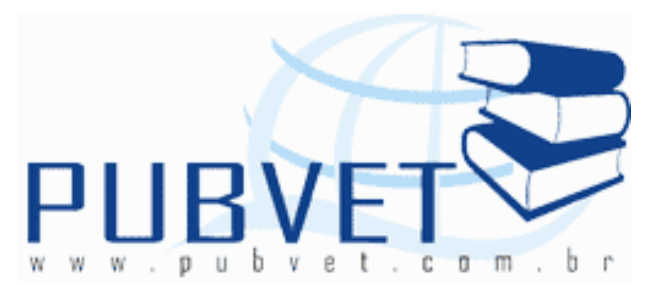

PUBVET, Publicações em Medicina Veterinária e Zootecnia.

\title{
Tratamento da cama de frango sobre o desempenho das aves e qualidade da carcaça e da cama - Revisão de literatura
}

\author{
Maria Cristina de Oliveira ${ }^{1 *}$ e Carlos Rosa Godoi ${ }^{2}$
}

${ }^{1}$ Faculdade de Medicina Veterinária, Universidade de Rio Verde, CEP 75901910, Rio Verde - GO, Brasil

${ }^{2}$ IF Goiano, Rio Verde, GO, Brasil

*Autor para correspondência: cristina@fesurv.br

\section{Resumo}

Condicionadores reduzem níveis de amônia nos galpões por reduzirem a atividade bacteriana na cama e por se ligar à amônia impedindo sua volatilização. A compostagem inativa vírus e bactérias em carcaças e camas. Altas concentrações de amônia reduzem a taxa de crescimento e a eficiência alimentar, danifica o trato respiratório e aumenta a susceptibilidade a doenças. A redução do $\mathrm{pH}$ e da população bacteriana pode ser benéfica para o desempenho das aves. Esta revisão de literatura foi realizada para analisar os efeitos dos tratamentos da cama de frango sobre desempenho, lesões na carcaça e qualidade da cama de frango.

Palavras chave: condicionadores da cama de frango, desempenho de frangos de corte, qualidade da cama de frango 


\title{
Broiler litter treatment on the broiler performance and litter quality - Literatura review
}

\begin{abstract}
Conditioners decrease ammonia levels in housings due the reduction of the bacterial activity in the litter and because they link to the ammonia, inhibiting its volatilization. Composting can inactive virus and bacteria in carcasses and broiler litters. High ammonia concentrations decrease the growth rate and the alimentary efficiency, cause damages to the respiratory tract and increase the susceptibility to the diseases. $\mathrm{pH}$ and bacterial population reduction can be beneficial to the bird performance. This literature review was carried out to analyze the effects of the poultry litter treatment on the performance, carcass lesions, and poultry litter quality.
\end{abstract}

Keywords: broiler litter conditioners, broiler litter quality, broiler performance

\section{Introdução}

A produção avícola ocorre em estruturas fechadas e com pisos cobertos por material absorvente (cama). As condições dentro desse confinamento são manejadas para otimizar a saúde e a produtividade das aves. A estrutura dos galpões, o controle ambiental, a ventilação, o manejo de comedouros e bebedouros, a saúde dos lotes, a densidade populacional, a qualidade da cama e o manejo das aves são fatores importantes na manutenção de um bom ambiente de produção. Como as aves gastam a maior parte de suas vidas em contato com a cama, a qualidade desta tem um efeito grande sobre a saúde e o desempenho delas.

É prática comum criar múltiplos lotes sobre camas reutilizadas. Entretanto, as camas úmidas, aderentes, com alto pH e produção excessiva de amônia, afetam negativamente o desempenho dos frangos (NAGARAJ et al., 2007). Durante as primeiras semanas de vida das aves, é importante que seu ambiente físico seja mantido em boas condições para que as máximas taxas de sobrevivência sejam alcançadas. Os aumentos do $\mathrm{pH}$, da temperatura e da 
OLIVEIRA, M.C. e GODOI, C.R. Tratamento da cama de frango sobre o desempenho das aves e qualidade da carcaça e da cama - Revisão de literatura. PUBVET, Londrina, V. 4, N. 7, Ed. 112, Art. 755, 2010.

umidade da cama, criam um ambiente favorável ao crescimento bacteriano. Além dos patógenos, que podem causar várias doenças, certas classes de bactérias benéficas também podem ser um problema, porque algumas delas podem degradar o ácido úrico $\mathrm{e}, \mathrm{a} \mathrm{NH}_{3}$, um subproduto desse processo, é liberada para o ambiente.

A amônia é um gás incolor que irrita as mucosas e não é percebido pelo olfato humano em níveis menores que 20ppm. Entretanto, concentrações superiores a 60ppm predispõem a doenças respiratórias e prejudicam a saúde das aves e dos seres humanos acarretando tosse, irritação ocular e fadiga (DONHAM, 2000; KOERKAMP et al., 2000).

As emissões de amônia das instalações animais reduz o valor da excreta como fertilizante e polui o meio ambiente. Assim, meios para reduzir as perdas de amônia associados com o alojamento animal, armazenamento dos dejetos, e aplicação ao solo terão efeitos positivos econômicos e ambientais.

Uma solução para o problema da emissão de amônia seria a redução da atividade bacteriana na cama de frango. Recentemente, vários condicionadores têm sido desenvolvidos, os quais reduzem significativamente os níveis de amônia nos galpões. Eles agem tanto por redução da atividade bacteriana na cama como por se ligar quimicamente à amônia e impedir sua volatilização.

Muito desses produtos são compostos ácidos e sua aplicação reduz o pH e a atividade de água da cama de frango, condições que afetam diretamente a sobrevivência de microrganismos presentes na cama. A redução de patógenos, por sua vez, reduz a transmissão horizontal entre lotes e resulta em menor freqüência de colonização intestinal e menos bactérias sobre a carcaça dos frangos nas instalações de processamento (LINE, 2002).

Dentes os condicionadores, podemos citar o ácido propiônico, o fosfato de cálcio monobásico e o ácido fosfórico $\left(\mathrm{H}_{3} \mathrm{PO}_{4}\right)$, o sulfato de ferro $\left.(\mathrm{FeSO})_{4}\right)$, o cloreto de alumínio $\left(\mathrm{AlCl}_{3}\right)$, o sulfato de alumínio $\left(\mathrm{Al}_{2}\left(\mathrm{SO}_{4}\right)_{3}\right)$, superfosfato simples $\left(\mathrm{Ca}\left(\mathrm{H}_{2} \mathrm{PO}_{4}\right)_{2} . \mathrm{H}_{2} \mathrm{O}\right)$ e bissulfato de sódio $\left(\mathrm{NaHSO}_{4}\right)$ têm sido usados com sucesso para reduzir o pH da cama, a volatilização de amônia e inibir a atividade microbiana (NAGARAJ et al., 2007). 
Outro tratamento da cama é a compostagem, que é a decomposição natural de materiais orgânicos por bactérias aeróbicas e fungos (De-ROUCHEY et al., 2005). A compostagem dentro dos galpões pode ser usada para conter e inativar vírus presentes em carcaças e camas, já que o processo produz calor, amônia e outros produtos que podem matar os vírus (MACKLIN et al., 2006; WILKINSON, 2007).

Assim, esta revisão de literatura foi realizada para analisar os tratamentos da cama de frango, bem como seus efeitos sobre o desempenho e sobre as lesões na carcaça das aves e sobre a qualidade da cama de frango.

\section{Efeito do tratamento da cama sobre o desempenho das aves}

Altas concentrações de amônia reduzem a taxa de crescimento e a eficiência alimentar, diminui a produção de ovos, danifica o trato respiratório e aumenta a susceptibilidade a doença como Newcastle (BENSON et al., 2008), aerosaculite ceratoconjuntivite (DO et al., 2005).

A adição de substâncias como o bissulfato de sódio (POPE \& CHERRY, 2000), ácido propiônico (GARRIDO et al, 2004), sulfato de alumínio (OLIVEIRA et al., 2004), cloreto de alumínio (CHOI \& MOORE, 2008) ou ácido cítrico (IVANOV, 2001) são opções para reduzir o pH da cama e, consequentemente, a população bacteriana produtora de amônia.

O bissulfato de sódio é um ácido efetivo em reduzir o pH e a volatilização da amônia da cama e, por isso, melhorar o desempenho das aves. TERZICH et al. (1998b) e McWARD \& TAYLOR (2000) demonstraram que frangos criados em camas tratadas com bissulfato de sódio tiveram menos problemas respiratórios e maiores ganhos de peso do que as criadas em camas nãotratadas. O bissulfato de sódio também reduziu a mortalidade associada à ascite (TERZICH et al., 1998a). A zeolita, material microporoso, também tem sido usado como tratamento da cama de frango e, segundo KARAMANLIS et al. (2008), o peso corporal aos 42 dias foi maior nas aves criadas sobre as camas tratadas com zeolita $(2317 \times 2468 \mathrm{~g})$. 
Entretanto, nem sempre é possível verificar melhora no desempenho produtivo das aves com o uso dos condicionadores, tais como sulfato de alumínio (MILES et al., 2003), superfosfato simples (FERREIRA et al., 2004), sulfato ferroso, cloreto de alumínio (DO et al., 2005) ou bissulfato de sódio (NAGARAJ et al., 2007).

A elevação do $\mathrm{pH}$ também pode ser benéfica na redução da concentração de bactérias na cama. Embora a adição de gesso agrícola ou cal não altera significativamente o pH da cama (OLIVEIRA et al., 2003), eles podem diminuir a presença de bactérias nas semanas iniciais de criação. Materiais tais como gesso agrícola $\left(\mathrm{CaCO}_{3}\right)$, cal hidratada $\left(\mathrm{Ca}(\mathrm{OH})_{2}\right)$ ou virgem $(\mathrm{CaO})$ aumentam a alcalinidade da cama (para pH maior que 7) e convertem mais íon amônio da cama em gás amônia, que é então liberada para a atmosfera, reduzindo o valor fertilizante da cama além de ter um impacto negativo sobre o meio ambiente.

Sendo assim, FERREIRA et al. (2004) estudaram a adição de gesso agrícola e cal hidratada na cama de frango submetida a três lotes de criação e não constaram diferenças no desempenho produtivo das aves. BENNETT et al. (2005), entretanto, ao incluírem na cama de frango 0 e 0,2\% de cal hidratada, observaram que aos 35 dias de idade, as aves criadas sobre as camas tratadas tinham maior peso corporal $(1406 \times 1465 \mathrm{~g})$, sendo o melhor desempenho associado às menores concentrações bacterianas nestas camas.

Os efeitos do uso de condicionadores na cama de frango sobre o desempenho produtivo não são conclusivos. É certo que, além do condicionador, outros fatores tais como o manejo da cama, ventilação, densidade populacional, manejo e tipo de bebedouros, etc podem influir na qualidade da cama e, consequentemente, no desempenho das aves. Assim, ainda são necessários estudos que avaliam a interação destes fatores.

\section{Efeito do tratamento da cama sobre lesões de carcaça}

A dermatite no coxim plantar em frangos tem ganhado grande importância devido ao aumento na exportação de pés de frangos. A forma 
OLIVEIRA, M.C. e GODOI, C.R. Tratamento da cama de frango sobre o desempenho das aves e qualidade da carcaça e da cama - Revisão de literatura. PUBVET, Londrina, V. 4, N. 7, Ed. 112, Art. 755, 2010.

mais prevalente de dermatite de coxim plantar em perus e frangos é a dermatite relacionada à umidade e formação de crostas na cama, causadas por uma combinação de umidade e irritantes químicos. Essa condição é usualmente chamada de dermatite de contato e pode também afetar o peito e joelhos.

As lesões variam de pontos escuros, associados com lesões leves na planta dos pés e que podem ser retiradas durante o processamento, até úlceras severas que causam inflamações que permanecem como tecidos epiteliais avermelhados após o processamento. Em casos mais severos, essas dermatites podem estar associadas a infecções bacterianas, especialmente com Staphylococcus aureus e Escherichia coli que são comumente encontradas na cama e nas aves (EICHNER et al., 2007).

A ulceração do coxim plantar é comum em perus que crescem em camas espessas e é, frequentemente, vista a partir de oito semanas de idade, aumentando sua prevalência quando a cama está úmida e com crostas. Os coxins plantares suportam o peso da ave quando em pé e lesões inflamatórias podem causar claudicação. Tais lesões, chamadas coletivamente, de pododermatite plantar, tem sido reconhecidas como uma causa de claudicação em perus em terminação e, consequentemente, sua significância econômica tem sido subestimada (MARTLAND, 1984).

A umidade da cama é considerada um fator predisponente à dermatite de contato. A umidade afeta a condição geral da cama e assim, espera-se que estimule a proliferação bacteriana, mas seu efeito direto sobre a dermatite de coxim plantar está mais provavelmente relacionado à seu impacto sobre a condição de superfície da cama. Quando o teor de umidade da cama excede $46 \%$, a superfície da cama se torna úmida e friável. Além da umidade, a friabilidade da superfície é também importante para a produção de queimaduras nos joelhos dos frangos, uma dermatite de contato dos joelhos. A aderência das excretas também causa um contato prolongado com substâncias corrosivas da cama (EICHNER et al., 2007). A amônia liberada da cama 
também pode causar irritação severa da pele das aves, resultando em pododermatite, queimaduras de joelhos e de peito (NAGARAJ et al., 2007).

Desta forma, o tratamento da cama com substâncias ácidas, que reduzam a formação de amônia (bissulfato de sódio, sulfato de alumínio, lama acidificada, entre outros) melhoraram a qualidade da carcaça de frangos de corte no que se refere à classificação, escores de lesões no peito e no coxim plantar (McWARD \& TAYLOR, 2000; NAGARAJ et al., 2007).

\section{Efeito do tratamento da cama sobre a qualidade da cama de frango}

A conversão de nitrogênio das excretas em amônia está relacionada à temperatura, umidade e $\mathrm{pH}$ da cama e taxa de ventilação (MILES, 2008). Normalmente, os níveis de amônia e a concentração de odor dentro de um galpão avícola alcançam um platô quando o peso total das aves alcança a sexta semana de idade (LACEY et al., 2004).

Os tratamentos ácidos da cama de frango reduzem a amônia volátil por reduzir o $\mathrm{pH}$, o qual altera o equilíbrio $\mathrm{NH}_{4}{ }^{+} / \mathrm{NH}_{3}$ em direção à formação de mais $\mathrm{NH}_{4}{ }^{+}$que não é volátil. REECE et al. (1979) demonstraram que a liberação de amônia era desprezível quando o pH da cama era menor que 7 . Entretanto, na medida em que $0 \mathrm{pH}$ se aproximava de 7 , a liberação de amônia começava, já que a uricase, enzima que cataliza a quebra do ácido úrico, alcança máxima atividade em pH 9.

Substâncias ácidas podem reduzir a volatilização de amônia por meio da redução do $\mathrm{pH}$ da cama, interagindo com o ácido úrico e por inibir o crescimento de populações microbianas que geram a amônia (NAGARAJ et al., 2007).

Em um experimento, NAGARAJ et al. (2007) estudaram os efeitos da adição de bissulfato de sódio em camas de frango no dia da chegada das aves e aos 21 dias de idade e relataram que o teor de umidade das camas não variou aos 35, 42 e 49 dias de criação, permanecendo em níveis de 10 a 18\%. Entretanto, os níveis de amônia até 35 dias de criação foram menores nas camas tratadas. 
OLIVEIRA, M.C. e GODOI, C.R. Tratamento da cama de frango sobre o desempenho das aves e qualidade da carcaça e da cama - Revisão de literatura. PUBVET, Londrina, V. 4, N. 7, Ed. 112, Art. 755, 2010.

O sulfato de alúminio também é efetivo em reduzir a amônia e ajuda a reduzir os custos com energia devido à menor necessidade de ventilação quando os níveis de amônia são menores (WORLEY et al., 2000). Recentes estudos demonstraram que o tratamento da cama com os níveis recomendados de sulfato de alumínio $(100 \mathrm{~g} / \mathrm{kg}$ de cama) apresenta pouco risco de toxicidade para as aves jovens devido ao consumo da cama (HUFF et al., 1996).

BURGESS et al. (1998) e SIMS \& LUKA-MCCAFFERTY (2002) avaliaram o uso de sulfato de alumínio em cama de frango e observaram que houve redução do pH das camas e aumento do teor de nitrogênio, não havendo, entretanto, alterações no teor de umidade. Já MEDEIROS et al. (2008) avaliaram a inclusão de superfosfato simples (0, 5, 10, 15, 20 e 25\%) em camas de 4 ciclos e relataram que a amônia volatilizada diminuiu após a inclusão de $15 \%$ e o pH reduziu de $8,4(0 \%)$ para 5,8 (25\%) linearmente com o aumento da inclusão do condicionador.

Tanto o bissulfato de sódio quanto o sulfato de alumínio fornecem prótons para o ambiente ( $n a$ forma de $\mathrm{H}^{+}$ou $\mathrm{H}_{3} \mathrm{O}^{+}$). A reação com a amônia gasosa $\left(\mathrm{NH}_{3}\right)$ para formar o cátion amônio não-volátil $\left(\mathrm{NH}_{4}{ }^{+}\right)$é um mecanismo pelo qual a amônia é removida do ambiente. Entretanto, a redução da amônia não está associada diretamente com a redução do $\mathrm{pH}$ da cama. O efeito desses condicionadores de cama sobre os níveis de amônia dura bem mais tempo do que o tempo em que ocorre a queda do pH. Este achado sugere que a redução do $\mathrm{pH}$ pode não ser o único mecanismo neste processo.

Mais recentemente, DO et al. (2005) utilizaram como tratamento da cama de frango o sulfato ferroso e cloreto de alumínio e verificaram que $\mathrm{opH}$ das camas não foi alterado, entretanto, o teor de umidade diminuiu nas camas tratadas com sulfato ferroso e cloreto de alumínio, comparado com camas não tratadas. A produção de amônia atmosférica das camas tratadas com sulfato ferroso $(2,88 \mathrm{ppm})$ e com sulfato de alumínio $(4,63 \mathrm{ppm})$ foi menor do que na cama controle $(31,88 \mathrm{ppm})$, na sexta semana. 
OLIVEIRA, M.C. e GODOI, C.R. Tratamento da cama de frango sobre o desempenho das aves e qualidade da carcaça e da cama - Revisão de literatura. PUBVET, Londrina, V. 4, N. 7, Ed. 112, Art. 755, 2010.

Substâncias alcalinas como a cal e o gesso agrícola também podem interferir na qualidade da cama. OLIVEIRA et al. (2003) compararam cama nova com cama reutilizada com e sem tratamentos (gesso agrícola e cal hidratada). Os autores observaram que as substâncias e o reuso da cama não interferiram com o teor de matéria seca, porém o menor valor de $\mathrm{pH}(6,97)$ e menor teor de amônia volatilizada $(11,29 \mathrm{mg} / \mathrm{kg})$ foram obtidos na cama contendo gesso agrícola, devido à redução do pH e à grande capacidade de retenção de umidade do gesso, o que reduz a sobrevivência de bactérias produtoras de amônia na cama.

A zeolita $\left[\left(\mathrm{Na}_{4} \mathrm{~K}_{4}\right)\left(\mathrm{Al}_{8} \mathrm{Si}_{40}\right) \mathrm{O}_{96} \cdot 24 \mathrm{H}_{2} \mathrm{O}\right]$ é um composto que troca cátions e que tem alta afinidade e seletividade por ions $\mathrm{NH}_{4}{ }^{+}$. Ela tem sido usada como um condicionador na cama de frango, no tratamento em digestores anaeróbicos para esterco bovino e em compostagem de dejetos de suínos e aves. A zeolita reduziu em mais de $44 \%$ a perda de amônia durante 56 dias de compostagem de dejetos avícolas com uma aplicação de $8 \%$ de zeolita (LI et al., 2008).

A aplicação tópica de zeolita em dejetos frescos de poedeiras diminuiu a emissão de amônia durante um período de armazenamento de 14 dias em 66, 91 e $96 \%$, respectivamente para taxas de aplicação de 2,5, 5 e 10\% (LI et al., 2008). Existem dois pontos de vista sobre os mecanismos de ação da zeolita. Primeiro, a amônia se liga a zeolita, o que leva a eliminação dos efeitos tóxicos do $\mathrm{NH}_{4}{ }^{+}$produzido pela atividade microbiana intestinal e, segundo, o efeito de retardar o trânsito da digesta que leva ao uso mais eficiente dos nutrientes (OLVER, 1997).

Outro tratamento da cama, que pode ser realizado entre lotes, é a compostagem dentro do galpão. MACKLIN et al. (2006) utilizaram cama submetida a dois e três lotes, tratadas por compostagem dentro do galpão e não-tratada. Os autores observaram que a compostagem reduziu bastante a presença de bactérias aeróbicas na cama devido a temperatura interna da pilha do composto, que deve ser mantida alta por longo período de tempo. Além do calor que é produzido nas pilhas, a amônia pode ter desempenhado 
um papel na redução bacteriana. MILES (2008) utilizaram cama de maravalha submetida a dois lotes e à compostagem dentro do galpão no período entre os lotes. Os autores reportaram que na superfície da pilha de compostagem a concentração média de amônia é maior $(11,2 \mathrm{ppm})$ do que no interior da pilha $(4,4 \mathrm{ppm})$, enfatizando a hipótese de que as aves estão sujeitas a maiores concentrações que podem não ser refletidas nas medidas feitas acima delas.

\section{Considerações finais}

O tratamento da cama com condicionadores químicos é uma solução rápida e econômica para amenizar problemas relacionados à volatilização da amônia, presença de patógenos e excesso de umidade da cama. Ao controlar estes fatores, o produtor consegue aumentar o número de lotes de frangos viáveis numa mesma cama. Normalmente, as camas de aviário são produzidas em larga escala nos atuais sistemas de produção de aves e tem em geral, como destino, o uso como fertilizantes e condicionadores de solo, pois são fontes de nutrientes, principalmente nitrogênio, fósforo e potássio e de matéria orgânica, que contribuem para a melhoria das características físicas, químicas e orgânicas do solo. Como os condicionadores evitam a volatilização de amônia, as camas tratadas geralmente apresentam níveis maiores de nitrogênio total e menores níveis de fósforo solúvel, dois minerais que representam grandes ameaças ao meio-ambiente.

Além dos condicionadores, a compostagem dentro dos galpões são realizadas, muitas vezes, de forma empírica, sem o domínio e conhecimento dos processos químicos e microbiológicos envolvidos. Desta forma, em muitos casos fica impossibilitada a aplicação da compostagem em grandes volumes de resíduos para produção de insumos agrícolas de forma contínua e padronizada.

Assim, é importante que mais estudos sejam realizados com o intuito de conhecer melhor as características das camas tratadas ou que sofreram compostagem dentro dos galpões quando utilizadas como fertilizante, já que esse é o destino final deste resíduo na maioria dos casos. 
OLIVEIRA, M.C. e GODOI, C.R. Tratamento da cama de frango sobre o desempenho das aves e qualidade da carcaça e da cama - Revisão de literatura. PUBVET, Londrina, V. 4, N. 7, Ed. 112, Art. 755, 2010.

\section{Referências bibliográficas}

BENNETT, D.S.; HIGGINS, S.E.; MOORE, R.; BYRD, J.A.; BELTRAN, R.; CORSIGLIA, C.; CALDWELL, D.; HARGIS, B.M. Effect of addition of hydrated lime to litter on recovery of selected bacteria and poult performance. Journal of Applied Poultry Research, Savoy, v.14, n. 4, p. 721-727, 2005.

BENSON, E.R.; MALONE, G.W.; ALPHIN, R.L.; JOHNSON, K.;.STAICU, E. Application of inhouse mortality composting on viral inactivity of Newcastle disease virus. Poultry Science, Savoy, v. 87, n. 4, p.627-635, 2009.

BURGESS, R.P.; CAREY, J.B.; SHAFER, D.J. The impact of $\mathrm{pH}$ on nitrogen retention in laboratory analysis of broiler litter. Poultry Science, Savoy, v. 77, n. 11, p. 1620-1622, 1998.

CHOI, I.H.; MOORE Jr, P.A. Effects of liquid aluminum chloride additions to poultry litter on broiler performance, ammonia emissions, soluble phosphorus, total volatile fatty acids, and nitrogen content of litter. Poultry Science, Savoy, v. 87, n. 10, p. 1955-1963, 2008.

De ROUCHEY, J.M.; HARNER, J.P.; MURPHY, J.P. Catastrophic mortality composting: is it safe and effective? Journal of Applied Poultry Research, Savoy, v. 14, n. 2, p. 414-416, 2005.

DO, J.C.; CHOI, I.H.; NAHM, K.H. Effects of chemically amended litter on broiler performances, atmospheric ammonia concentration, and phosphorus solubility in litter. Poultry Science, Savoy, v. 84, n. 5, p. 679-686, 2005.

DONHAM, K.J. Occupational health hazards and recommended exposure limits for workers in poultry buildings. National Poultry Waste Management Symposium, 2000, Auburn, EUA. Proceedings... Auburn: Auburn University, 2000. p. 92-109, 2000.

EICHNER, G.; VIEIRA, S.L.; TORRES, C.A.; CONEGLIAN, J.L.B.; FREITAS; D.M.; OYARZABAL, O.A. Litter moisture and footpad dermatitis as affected by diets formulated on an all-vegetable basis or having the inclusion of poultry by-product. Journal of Applied Poultry Research, Savoy, v. 16, n. 3, p. 344-350, 2007.

FERREIRA, H.A.; OLIVEIRA; M.C.; TRALDI, A.B. Efeito de condicionadores químicos na cama de frango sobre o desempenho de frangos de corte. Arquivo Brasileiro de Medicina Veterinária e Zootecnia, Belo Horizonte, v. 56, n. 4, p. 542-546, 2004.

GARRIDO, N.M.; SKJERVHEIN, M.; OPPEGAARD, H.; SORUM, H. Acidified litter benefits the intestinal flora balance of broiler chickens. Applied and Environmental Microbiology, Washington, D.C., v. 70, n. 9, p. 5208-5213, 2004.

HUFF, W.E.; MOORE Jr, P.A.; BALOG, J.M.; BAYYARI, G.R.; RATH, N.C. Evaluation of the toxicity of alum (aluminum sulfate) in young broiler chicks. Poultry Science, Savoy, v. 75, n. 11 , p. $1359-1364,1996$.

IVANOV, I.E. Treatment of broiler litter with organic acids. Research in Veterinary Science, Amsterdam, v. 70, n. 2, p. 169-173, 2001.

KARAMANLIS, X.; FORTOMARIS, P.; ARSENOS, G.; DOSIS, I.; PAPAIOANNOU, D.; BATZIOS, C.; KAMARIANOS, A. The effect of a natural zeolite (clinoptilolite) on the performance of broiler chickens and the quality of their litter. Asian-Australasian Journal of Animal Science, Seoul, v. 21, n. 11, p. 1642-1650, 2008.

KOERKAMP, P.W.G.G.; MIDDELKOOP, J.H.; ELLEN, H.H. Air quality management and requirements in Europe. In: National Poultry Waste Management Symposium, 2000, Auburn, EUA. Proceedings... Auburn: Auburn University, 2000. p. 72-79.

LACEY, R.E.; MUKHTAR, S.; CAREY, J.B.; ULLMAN, J.L. A review of literature concerning odors, ammonia, and dust from broiler production facilities: 1 . odor concentrations and emissions. Journal of Applied Poultry Research, Savoy, v. 13, n. 3, p. 500-508, 2004.

LI, H.; XIN, H.; LIANG, Y.; BURNS, R.T. Reduction of ammonia emissions from stored laying hen manure through topical application of zeolite, Al+Clear, Ferix-3, or poultry litter treatment. Journal of Applied Poultry Research, Savoy, v. 17, n. 4, p. 421-431, 2008.

LINE, J.E. Campylobacter and Salmonella populations associated with chickens raised on acidified litter. Poultry Science, Savoy, v. 81, n. 10, p. 1473-1477, 2002.

MACKLIN, K.S.; HESS, J.B.; BILGILI, S.F.; NORTON, R.A. Effects of in-house composting of litter on bacterial levels. Journal of Applied Poultry Research, Savoy, v. 15, n. 4, p. 531-537, 2006. 
OLIVEIRA, M.C. e GODOI, C.R. Tratamento da cama de frango sobre o desempenho das aves e qualidade da carcaça e da cama - Revisão de literatura. PUBVET, Londrina, V. 4, N. 7, Ed. 112, Art. 755, 2010.

MARTLAND, M.F. Wet litter as a cause of plantar pododermatitis, leading to foot ulceration and lameness in fattening turkeys. Avian Pathology, Londres, v. 13, n. 2, p. 241-252, 1984.

McWARD, G.W.; TAYLOR, D.R. Acidified clay litter amendment. Journal of Applied Poultry Research, Savoy, v. 9, n. 4, p. 518-529, 2000.

MEDEIROS, R.; SANTOS, B.J.M.; FREITAS, M.; SILVA, O.A.; ALVES, F.F.; FERREIRA, E. A adição de diferentes produtos químicos e o efeito da umidade na volatilização de amônia em cama de frango. Ciência Rural, Santa Maria, v. 38, n. 8, p. 2321-2326, 2008.

MILES, D.M. Vertical stratification of ammonia in a broiler house. Journal of Applied Poultry Research, Savoy, v. 17, n. 3, p. 348-353, 2008.

MILES, D.M.; MOORE Jr, P.A.; SMITH, D.R.; RICE, D.W.; STILBORN, H.L.; ROWE, D.R.; LOTT, B.D.; BRANTON, S.L.; SIMMONS, J.D. Total and water-soluble phosphorus in broiler litter over three flocks with alum litter treatment and dietary inclusion of high available phosphorus corn and phytase supplementation. Poultry Science, Savoy, v. 82, n. 10, p. 1544-1549, 2003.

NAGARAJ, M.; WILSON, C.A.P.; SAENMAHAYAK, B.; HESS, J.B.; BILGILI, S.F. Efficacy of a litter amendment to reduce pododermatitis in broiler chickens. Journal of Applied Poultry Research, Savoy, v. 16, n. 2, p. 255-261, 2007.

OLIVEIRA, M.C.; ALMEIDA, C.V.; ANDRADE, D.O.; RODRIGUES, S.M.M. Teor de matéria seca, $\mathrm{pH}$ e amônia volatilizada da cama de frango tratada ou não com diferentes aditivos. Revista Brasileira de Zootecnia, Viçosa, v. 32, n. 4, p. 951-954, 2003.

OLIVEIRA, M.C.; FERREIRA, H.A.; CANCHERINI, L.C. Efeito de condicionadores químicos sobre a qualidade da cama de frango. Arquivo Brasileiro de Medicina Veterinária e Zootecnia, Belo Horizonte, v. 56, n. 4, p. 536-541, 2004.

OLVER, M.D. Effect of feeding clinoptilolite zeolite on the performance of three strains of laying hens. British Poultry Science, Londres, v. 38, n. 2, p. 220-222, 1997.

POPE, M.J.; CHERRY, T.E. An evaluation of the presence of pathogens on broilers raised on poultry litter treatment-treated litter. Poultry Science, Savoy, v. 79, n. 9, p. 1351-1355, 2000.

REECE, F.N.; BATES, B.J.; B.D. LOTT, B.D. Ammonia control in broiler houses. Poultry Science, Savoy, v. 58, n. 6, p. 754-755, 1979.

SIMS, J.T.; LUKA-MCCAFFERTY, N.J. On-farm evaluation of aluminum sulfate (alum) as a poultry litter amendment: effects on litter properties. Journal of Environmental Quality, Madison, v. 31, n. 6, p. 2056-2073, 2002.

TERZICH, M.; QUARLES, C.; GOODWIN, M.A.; BROWN, J. Effect of poultry litter treatment (PLT) on death due to ascites in broilers. Avian Diseases, Jacksonville, v. 43, n. 2, p. 385-387, 1998a.

TERZICH, M.; QUARLES, C.; GOODWIN, M.A.; BROWN, J. Effect of poultry litter treatment (PLT) on the development of respiratory tract lesions in broilers. Avian Pathology, Londres, v. 27, n. 6, p. 566-569, 1998 b.

WILKINSON, K.G. The biosecurity of on-farm mortality composting. Journal of Applied Microbiology, Hoboken, v. 102, n. 3, p. 609-618, 2007.

WORLEY, J.W.; CABRERA, M.L.; RISSE, L.M. Reduced levels of alum to amend broiler litter. Applied Engineering in Agriculture, St. Joseph, v. 16, n. 4, p. 441-444, 2000. 